\title{
Comparison of selected canine vector-borne diseases between urban animal shelter and rural hunting dogs in Korea
}

\author{
Sun Lim¹, Peter J Irwin², SeungRyong Lee33, MyungHwan Oh³, KyuSung Ahn³, BoYoung Myung ${ }^{4}$ and SungShik Shin*3
}

\begin{abstract}
A serological survey for Dirofilaria immitis, Anaplasma phagocytophilum, Ehrlichia canis, and Borrelia burgdorferi infections in rural hunting and urban shelter dogs mainly from southwestern regions of the Republic of Korea (South Korea) was conducted. From a total of 229 wild boar or pheasant hunting dogs, the number of serologically positive dogs for any of the four pathogens was 93 (40.6\%). The highest prevalence observed was D. immitis (22.3\%), followed by A. phagocytophilum (18.8\%), E. canis (6.1\%) and the lowest prevalence was B. burgdorferi (2.2\%). In contrast, stray dogs found within the city limits of Gwangju showed seropositivity only to D. immitis (14.6\%), and none of the 692 dogs responded positive for A. phagocytophilum, E. canis or B. burgdorferi antibodies. This study indicates that the risk of exposure to vector-borne diseases in rural hunting dogs can be quite high in Korea, while the urban environment may not be suitable for tick infestation on dogs, as evidenced by the low infection status of tick-borne pathogens in stray dogs.
\end{abstract}

\section{Findings}

The situation with respect to parasitic diseases of companion animals in the Republic of Korea (South Korea) still remains relatively uninvestigated. Especially, limited information is available on the status of vector-borne disease transmission among dogs and cats. As global warming is affecting climate conditions of Korea, subtropical parasitic diseases such as malaria that has not been established in South Korea are now emerging [1].

Canine vector-borne pathogens which include Dirofilaria spp., Anaplasma spp., Ehrlichia spp., Borrelia spp. and others can elicit serious illness in domestic dogs. These agents can also cause clinical illness such as human dirofilariasis as a result of accidental infection [2]. Lyme disease, anaplasmosis, and infections with Ehrlichia canis have been reported in humans, too [3-5]. Canine vectorborne diseases have been found throughout major continents of the world [6,7]. In Japan, the prevalence of $E$. canis was $4.7 \%$ [8] while that of B. burgdorferi was $8.8 \%$ in dogs [9]. In Korea, little information is available regarding the occurrence of these diseases in dogs, although the

\footnotetext{
* Correspondence: sungshik@jnu.ac.kr

${ }^{3}$ College of Veterinary Medicine, Chonnam National University, Gwangju 500757 , Korea

Full list of author information is available at the end of the article
}

prevalence in ticks and small mammals has been well documented [10,11]. With regard to the dog, most studies on vector-borne diseases have focused on canine heartworm disease, which has a prevalence ranging from $9.9 \%$ to $50.3 \%$ [12-16]. Since outdoor dogs such as hunting, military or stray dogs are vulnerable to vector-borne pathogens, we investigated the prevalence of $D$. immitis, A. phagocytophilum, E. canis, and B. burgdorferi among hunting and stray dogs from Korea.

From December of 2007 to August of 2009, blood samples were collected from 229 hunting dogs in Beolgyo, Gwangyang, Suncheon, and Asan areas of South Korea. These areas are located from $34^{\circ} 50^{\prime} \mathrm{N}$ to $35^{\circ} 05^{\prime} \mathrm{N}$ latitude and from $127^{\circ} 15^{\prime} \mathrm{E}$ to $127^{\circ} 34^{\prime} \mathrm{E}$ longitude (southwestern region of South Korea) except for Asan which is located $36^{\circ} 45^{\prime} \mathrm{N}$ latitude and $126^{\circ} 89^{\prime} \mathrm{E}$ longitude (midwestern region of South Korea). Dogs included in this study were raised for the purpose of hunting either pheasants or wild boars with an average of 3.2 years of age and an average body weight of $23.3 \mathrm{Kg}$. The majority of dogs were cross breeds of German Shorthaired Pointer, and were composed of $145(63.3 \%)$ male and $84(36.7 \%)$ female dogs. Blood samples were also collected from a total of 692 stray dogs admitted to the Gwangju Animal 
Shelter from January to December of 2009. The city of Gwangju, with a population of 1.4 million people in December 2009, is also located in the southwestern region of Korea where Beolgyo, Gwangyang and Suncheon is situated within the distance of $100 \mathrm{Km}$ from the city. The majority of stray dogs admitted to the only shelter of the city were either small- or middle-sized breeds with an average body weight of $4.0 \mathrm{Kg}$. Among them, Maltese (27.0\%), mixed breeds (21.4\%), Shih Tzu (16.0\%), Yorkshire terrier (11.0\%), and Poodle (7.5\%) were the most commonly found breeds. Blood samples collected from dogs were tested using a commercial ELISA assay kit (SNAP ${ }^{\circ}$ 4Dxं IDEXX Laboratories, Inc. U.S.A.) which detects $D$. immitis antigen, and antibodies specific to $A$. phagocytophilum (synthetic peptide from the major surface protein (p44/MSP2)), E. canis (P30 and P30-1 outer membrane proteins), and B. burgdorferi (C6 peptide). A test of independence for significance of the relationship between categorical variables (gender, age, and geographic regions) was made via Pearson's chi-Square test and Fisher's exact test for expected counts under five using SPSS 17.0 (SPSS Inc., Chicago, IL, USA).

The serological prevalence of $D$. immitis, A phagocytophilum, E. canis, and B. burgdorferi in hunting dogs from Korea is shown in Table 1. The number of dogs serologically positive with any of the four pathogens surveyed in this study was 93 (40.6\%). The number of dogs with sin- gle, dual or triple seropositivity was 75 (32.8\%), 16 (7.0\%), and $2(0.9 \%)$, respectively. The highest prevalence was observed in D. immitis (22.3\%), followed by A. phagocytophilum (18.8\%), and the lowest by B. burgdorferi $(2.2 \%)$. Although a significant variation in geographical origin was observed in E. canis Ab $\left(\chi^{2}=7.968, p=0.032\right.$ : Fisher's exact test), the overall exposure of dogs to these pathogens was irrelevant to geographical locality $\left(\chi^{2}=0.848, p\right.$ $=0.838$ ). The number of serologically positive dogs was similar between male (41.4\%) and female $\left(39.3 \%, X^{2}=\right.$ 0.097, $p=0.756$ ), but dogs of above two years in age $(45.3 \%)$ were significantly more exposed to these pathogens than younger dogs $\left(24.0 \%, \chi^{2}=7.318, p=0.007\right)$ which was mostly influenced by the exposure of the dogs to $D$. immitis $\left(\chi^{2}=7.525, p=0.006\right)$.

The seroprevalence of selected arthropod-borne pathogens in stray dogs admitted to the Gwangju Animal Shelter during the year 2009 is shown in Table 2. Unlike the hunting dogs raised and living outside of the city, stray dogs found within the city limit of Gwangju showed seropositivity only to $D$. immitis (14.6\%) and none of the 692 dogs responded positive for A. phagocytophilum, E. canis or B. burgdorferi antibodies. The number of serologically positive dogs was significantly more in female $(17.9 \%)$ than in male $\left(12.4 \%, \mathrm{X}^{2}=4.014, p=0.045\right)$, and dogs of more than two years old were significantly more exposed

Table 1: Seroprevalence of selected arthropod-borne pathogens in hunting dogs from Korea as detected by a commercial screening test

Number(\%) of positive dogs by SNAP 4Dx test

\begin{tabular}{|c|c|c|c|c|c|c|c|}
\hline \multirow[b]{2}{*}{ Category } & & \multirow[b]{2}{*}{ Dogs examined (\%) } & \\
\hline & & & $\mathrm{Di} \mathbf{A g}$ & Ap Ab & $E c A b$ & $\mathbf{B b} \mathbf{A b}$ & Total ${ }^{*}$ \\
\hline \multirow[t]{2}{*}{ Gender } & Female & $84(36.7)$ & $23(27.4)$ & 13(15.5) & $3(3.6)$ & $2(2.4)$ & $33(39.3)$ \\
\hline & Male & $145(63.3)$ & 28(19.3) & $30(20.7)$ & $11(7.6)$ & $3(2.1)$ & $60(41.4)$ \\
\hline \multirow[t]{2}{*}{ Age(year) } & $<2$ & $50(21.8)$ & $4(8.0)$ & $5(10.0)$ & $3(6.0)$ & $0(0.0)$ & $12(24.0)$ \\
\hline & $>=2$ & $179(78.2)$ & $47(26.3)$ & $38(21.2)$ & $11(6.1)$ & $5(2.8)$ & $81(45.3)$ \\
\hline \multirow{4}{*}{$\begin{array}{l}\text { Geographical } \\
\text { origin }\end{array}$} & Beolgyo & $32(14.0)$ & $7(21.9)$ & $6(18.8)$ & $4(12.5)$ & $2(6.3)$ & $14(43.8)$ \\
\hline & Gwangyang & $65(28.4)$ & 18(27.7) & $7(10.8)$ & $3(4.6)$ & $0(0.0)$ & $27(41.5)$ \\
\hline & Suncheon & $26(11.4)$ & $2(7.7)$ & $7(26.9)$ & $4(15.4)$ & $1(3.8)$ & $12(46.2)$ \\
\hline & Asan & $106(46.3)$ & $24(22.6)$ & $23(21.7)$ & $3(2.8)$ & $2(1.9)$ & $40(37.7)$ \\
\hline Total & & $229(100.0)$ & $51(22.3)$ & $43(18.8)$ & $14(6.1)$ & $5(2.2)$ & $93(40.6)$ \\
\hline
\end{tabular}

*Number of positive dogs by any of the four test results by SNAP 4Dx test

Di Ag, Dirofilaria immitis antigen; Ap Ab, Anaplasma phagocytophilum antibody; Ec Ab, Ehrlichia canis antibody; Bb Ab, Borrelia burgdorferi antibody 
Table 2: Seroprevalence of selected arthropod-borne pathogens in stray dogs admitted to a shelter in Gwangju, Korea as detected by a commercial screening test

\begin{tabular}{|c|c|c|c|c|c|c|c|}
\hline \multirow[b]{2}{*}{ Category } & & \multirow[b]{2}{*}{ Dogs examined (\%) } & \multicolumn{5}{|c|}{ Number(\%) of positive dogs by SNAP 4Dx test } \\
\hline & & & Di Ag & Ap Ab & $\mathbf{E c} \mathbf{A b}$ & $\mathbf{B b} \mathbf{A b}$ & Total* \\
\hline \multirow[t]{2}{*}{ Gender } & Female & $280(40.5)$ & $50(17.9)$ & $0(0.0)$ & $0(0.0)$ & $0(0.0)$ & $50(17.9)$ \\
\hline & Male & $412(59.5)$ & $51(12.4)$ & $0(0.0)$ & $0(0.0)$ & $0(0.0)$ & $51(12.4)$ \\
\hline \multirow[t]{2}{*}{ Age(yr) } & $<2$ & $211(30.5)$ & $19(9.0)$ & $0(0.0)$ & $0(0.0)$ & $0(0.0)$ & $19(9.0)$ \\
\hline & $>=2$ & $481(69.5)$ & $82(17.0)$ & $0(0.0)$ & $0(0.0)$ & $0(0.0)$ & $82(17.0)$ \\
\hline \multirow{5}{*}{$\begin{array}{l}\text { Geographical } \\
\text { origin (district) }\end{array}$} & East & $58(8.4)$ & $12(20.7)$ & $0(0.0)$ & $0(0.0)$ & $0(0.0)$ & $12(20.7)$ \\
\hline & West & $105(15.2)$ & $15(14.3)$ & $0(0.0)$ & $0(0.0)$ & $0(0.0)$ & $15(14.3)$ \\
\hline & South & $87(12.6)$ & $13(14.9)$ & $0(0.0)$ & $0(0.0)$ & $0(0.0)$ & 13(14.9) \\
\hline & North & $355(51.3)$ & $53(14.9)$ & $0(0.0)$ & $0(0.0)$ & $0(0.0)$ & $53(14.9)$ \\
\hline & Gwangsan & $87(12.6)$ & $8(9.2)$ & $0(0.0)$ & $0(0.0)$ & $0(0.0)$ & $8(9.2)$ \\
\hline Total & & $692(100.0)$ & $101(14.6)$ & $0(0.0)$ & $0(0.0)$ & $0(0.0)$ & $101(14.6)$ \\
\hline
\end{tabular}

*Number of positive dogs by any of the four test results by SNAP 4Dx test

$\mathrm{Di}$ Ag, Dirofilaria immitis antigen; Ap Ab, Anaplasma phagocytophilum antibody; Ec Ab, Ehrlichia canis antibody; Bb Ab, Borrelia burgdorferi antibody

to these pathogens than younger dogs $\left(\chi^{2}=7.611, p=\right.$ 0.006).

This study strongly indicates that dogs from Korea are potentially vulnerable to exposure to major canine vector-borne diseases, as evidenced by the relatively high prevalence rates of both mosquito- and tick-borne pathogens in hunting dogs. Previous reports also indicate that vector-borne pathogens such as $E$. chaffeensis, $A$. phagocytophilum, and $A$. bovis were identified by TaqMan realtime PCR [17] from ticks collected from various areas of Korea. Also, five species of ticks in two genera (Haemaphysalis spp. and Ixodes spp.) collected from small wildcaught mammals or by dragging/flagging in Korea contained species-specific fragments of A. phagocytophilum, A. platys, E. chaffeensis, E. ewingii, E. canis, and Rickettsia rickettsii, as evidenced by the PCR assay [10].

While infection status of the mosquito-transmitted $D$. immitis infection was relatively high in both hunting and stray dogs, the tick-borne pathogens were present only in hunting dogs. Two factors may be involved to explain the result. First, although $38.9 \%$ of the 501 million $\mathrm{m} 2$ land of the city of Gwangju is covered with woods and fields, it is presumed that wild animals that can transmit ticks to dogs are rarely able to enter or persist in the urban environment. Secondly, the floor of people's homes has a special place in the culture of Koreans; it is generally polished and un-carpeted, on which they sit and often sleep. People always remove their shoes when entering a Korean home because a dirty floor is seldom tolerated in a Korean home. As the result, ticks and fleas are rarely found infesting urban indoor dogs of Korea. For the same reason, small dogs like Maltese, Yorkshire, and Shi Tzu are commonly preferred by pet owners in Korea because they are well adapted to being apartment dwellers. Stray dogs admitted to the Gwangju Animal Shelter very much represent dog breeds favoured by urban-dwelling Koreans; Maltese, Shih Tzu, Yorkshire terrier, Poodle, and Schnauzer, etc [18].

While mosquitoes are ever-present in the city environment and even indoor-only dogs can get bitten by them, this study indicates that ticks, in contrast, may have limited access to the city environment of Korea. Similar results were observed in 2008 from a previous study on the infection status of stray dogs at the same animal shelter as investigated in this study in which 130 of 1,143 stray dogs (11.4\%) showed positive reaction to D. immitis on SNAP $^{\circ} 3 \mathrm{Dx}^{\circ}$ test, while only one dog each showed seropositive to E. canis and B. burgdorferi, respectively [18].

Since the first report of $D$. immitis in dogs from Korea was published in 1962 [19], there have been several studies on the epidemiology of canine dirofilariasis in Korea. The prevalence of $D$. immitis for instance, was $31.2 \%$ 
using an antigen test (Heartworm SNAP $^{\circ}$ test, IDEXX, Inc.) in outdoor dogs and $2.8 \%$ in indoor dogs from Busan, Korea [12], and that in German shepherd using and antigen test (DiroCHEK ${ }^{\circ}$, Synbiotics Co., USA) was $28.3 \%$ [13]. In our studies, the prevalence of $D$. immitis in both hunting and stray dogs was similar to those of previous studies on outdoor dogs. In contrast to relatively low prevalence rate in dogs from the USA (1.4\%) [20], the prevalence of $D$. immitis in dogs from Korea was high in general, possibly because of better public apprehension and prophylactic programs carried in the USA than in Korea.

Little information is available about the infection status of dogs with $A$. phagocytophilum which is also responsible for human granulocytic anaplasmosis [21]. Although the prevalence of $A$. phagocytophilum in ticks collected from small mammals at U.S. military installations and training sites was $25.9 \%$ as identified by DNA analysis in Korea [10], only one clinical case due to A. platys has so far been reported in dogs [22], and our study is the first report about seroprevalence of $A$. phagocytophilum in dogs from Korea. In the USA, the mean prevalence of $A$. phagocytophilum seroreactivity in dogs was reported to be $4.8 \%$ by $\mathrm{SNAP}^{\circ} 4 \mathrm{Dx}^{\circ}$ test [20]. In contrast to previous studies, hunting dogs in our study show a high prevalence of $A$. phagocytophilum seroreactivity (18.8\%), presumably due to frequent exposure of dogs to vector ticks during hunting in wooded mountains of Korea. Information on the species of ticks collected from hunting dogs in our study will be available in a separate article. It is possible that some dogs with seroreactivity to $A$. phagocytophilum were actually seropositive for $A$. platys because both $A$. phagocytophilum and $A$. platys exist among ticks in Korea [10] and because the SNAP $4 \mathrm{Dx}^{\circ}$ cannot distinguish infection between $A$. phagocytophilum and A. platys in dogs. Further molecular-based studies will be necessary to distinguish between these two pathogens in seropositive dogs.

The prevalence of $E$. canis in ticks of Korea was $1.1 \%$, as identified by DNA analysis [10], and the seroprevalence of $E$. canis in dogs (German shepherd) using the IDEXX ${ }^{\circ}$ $3 \mathrm{Dx}$ test was reported to be $13 \%$ in female and $11.6 \%$ in male [23]. Both E. canis and E. chaffeensis are present in Korea, as detected from ticks [10]. Since SNAP $3 \mathrm{Dx}^{\circ}$ and $4 \mathrm{Dx}^{\circ}$ tests are known not to be able to distinguish between $E$. canis and E. chaffeensis infections in dogs [24], it will be necessary to distinguish them by further investigation.

B. burgdorferi is a zoonotic pathogen because it causes Lyme disease in humans and infects some domestic mammals including dogs. In Korea, the seroprevalence of B. burgdorferi was reported to be $2.6 \%$ in female and $5.8 \%$ in male German shepherd dogs [23] and more than 4 clinical human cases have been reported [25]. B. burgdorferi was also isolated from ticks in 1992 [26]. The seroprevalence rate of B. burgdorferi in dogs was $1.3 \%$ in U.S [20] and $0.6 \%$ in Spain [27]. In our studies, the prevalence of $B$. burgdorferi in hunting dogs $(2.2 \%)$ was similar to that of a previous study in German shepherd dogs in Korea [23].

In conclusion, this study indicates that hunting dogs are frequently exposed to $D$. immitis, A. phagocytophilum, $E$. canis, and $B$. burgdorferi in Korea while urban stray dogs are exposed mainly to $D$. immitis. Since canine vectorborne diseases can cause severe clinical illness such as pulmonary disease, lameness, fever and anorexia and can also potentially cause severe diseases in humans, dogs must be examined for the presence of vector-borne diseases.

\section{Competing interests}

The authors declare that they have no competing interests.

\section{Authors' contributions}

SL, PJI, SRL and SSS conceived the paper and wrote the manuscript. MHO, KSA and BYM assisted in laboratory studies.

\section{Acknowledgements}

This study is supported in part by a grant from the Australia-Korea Foundation of the Department of Foreign Affairs and Trade, PO Box 5050, Kingston Act 2604, Australia and the graduate fellowship provided by the Korean Ministry of Education, Science and Technology through the Brain Korea 21 project.

Publication of this thematic series has been sponsored by Bayer Animal Health $\mathrm{GmbH}$.

\section{Author Details}

${ }^{1}$ Biotherapy Human Resources Center (BK21), Chonnam National University, Gwangju 500-757, Korea, ${ }^{2}$ Australasian Centre for Companion Animal Research, School of Veterinary and Biomedical Sciences, Murdoch University, Murdoch 6150, WA, Australia, ${ }^{3}$ College of Veterinary Medicine, Chonnam National University, Gwangju 500-757, Korea and ${ }^{4}$ Gwangju Animal Shelter, Gwangju 500-757, Korea

Received: 9 February 2010 Accepted: 8 April 2010

Published: 8 April 2010

\section{References}

1. Kim HC, Pacha LA, Lee WJ, Lee JK, Gaydos JC, Sames WJ, Lee HC, Bradley K, Jeung GG, Tobler SK, Klein TA: Malaria in the Republic of Korea, 19932007. Variables related to re-emergence and persistence of Plasmodium vivax among Korean populations and U.S. forces in Korea. Mil Med 2009, 174:762-769.

2. Miyoshi T, Tsubouchi H, Iwasaki A, Shiraishi T, Nabeshima K, Shirakusa T: Human pulmonary dirofilariasis: a case report and review of the recent Japanese literature. Respirology 2006, 11:343-347.

3. Shapiro ED, Gerber MA: Lyme disease. Clin Infect Dis 2000, 31:533-542

4. Perez M, Bodor M, Zhang C, Xiong Q, Rikihisa Y: Human infection with Ehrlichia canis accompanied by clinical signs in Venezuela. Ann NY Acad Sci 2006, 1078:110-117

5. Kocianova E, Kost'anova Z, Stefanidesova K, Spitalska E, Boldis V, Huckova D, Stanek G: Serologic evidence of Anaplasma phagocytophilum infections in patients with a history of tick bite in central Slovakia. Wien Klin Wochenschr 2008, 120:427-431.

6. Otranto D, Dantas-Torres F, Breitschwerdt EB: Managing canine vectorborne diseases of zoonotic concern: part one. Trends Parasito/ 2009, 25:157-163.

7. Irwin PJ: Canine babesiosis: from molecular taxonomy to control. Parasit Vectors 2009, 2(Suppl 1):\$4 
8. Inokuma H, Ohno K, Yamamoto S: Serosurvey of Ehrlichia canis and Hepatozoon canis infection in dogs in Yamaguchi Prefecture, Japan. J Vet Med Sci 1999, 61:1153-1155.

9. Isogai E, Isogai H, Sato N, Yuzawa M, Kawakami M: Antibodies to Borrelia burgdorferi in dogs in Hokkaido. Microbiol Immunol 1990, 34:1005-1012.

10. Kim CM, Yi YH, Yu DH, Lee MJ, Cho MR, Desai AR, Shringi S, Klein TA, Kim HC, Song JW, Baek LJ, Chong ST, O'guinn ML, Lee JS, Lee IY, Park JH, Foley J, Chae JS: Tick-borne rickettsial pathogens in ticks and small mammals in Korea. Appl Environ Microbiol 2006, 72:5766-5776.

11. Kim CM, Kim JY, Yi YH, Lee MJ, Cho MR, Shah DH, Klein TA, Kim HC, Song JW, Chong ST, O'Guinn ML, Lee JS, Lee IY, Park JH, Chae JS: Detection of Bartonella species from ticks, mites and small mammals in Korea. J Vet Sci 2005, 6:327-334.

12. Byeon KH, Kim BJ, Kim SM, Yu HS, Jeong HJ, Ock MS: A serological survey of Dirofilaria immitis infection in pet dogs of Busan, Korea, and effects of chemoprophylaxis. Korean J Parasitol 2007, 45:27-32.

13. Lee JC, Lee CY, Shin SS, Lee CG: A survey of canine heartworm infections among German shepherds in South Korea. Korean J Parasitol 1996, 34:225-231

14. Byun JW, Park YI, Lee OS, Shim HS, Cho KM, Yoon SS: Prevalence of canine dirofilariasis of the stray dogs in Korea. Korean J Vet Pub Health 2007, 31:15-19.

15. Song KH, Lee SE, Hayasaki M, Shiramizu K, Kim DH, Cho KW: Seroprevalence of canine dirofilariosis in South Korea. Vet Parasitol 2003, 114:231-236.

16. Wee SH, Lee JG, Kim JT: Prevalence of Dirofilaria immitis infection in dogs of Chuncheon area. Korean J Vet Pub Health 2001, 25:229-232.

17. Kim CM, Kim MS, Park MS, Park JH, Chae JS: Identification of Ehrlichia chaffeensis, Anaplasma phagocytophilum, and A. bovis in Haemaphysalis longicornis and Ixodes persulcatus ticks from Korea. Vector Borne Zoonotic Dis 2003, 3:17-26.

18. Myung BY, Yi YK, Paik IY, Chung GM, Lim S, Suh GH, Kang SS, Shin SS: The disease status of stray dogs admitted to an animal shelter in Gwangju, Korea. Korean J Vet Res 2009, 49:297-307.

19. Bak UB, Lee HS: Studies on the infection rate of Dirofilaria immitis in Chinju area by use of blood test and intracutaneous test. Jinju Agr Univ Report 1962, 1:54-58.

20. Bowman D, Little SE, Lorentzen L, Shields J, Sullivan MP, Carlin EP: Prevalence and geographic distribution of Dirofilaria immitis, Borrelia burgdorferi, Ehrlichia canis, and Anaplasma phagocytophilum in dogs in the United States: results of a national clinic-based serologic survey. Vet Parasitol 2009, 160:138-148.

21. Rodgers SJ, Morton RJ, Baldwin CA: A serological survey of Ehrlichia canis, Ehrlichia equi, Rickettsia rickettsii, and Borrelia burgdorferi in dogs in Oklahoma. J Vet Diagn Invest 1989, 1:154-159.

22. Lee SJ, Lee MJ, Chae JS, Na KJ: Diagnosis of anaplasmosis by PCR and long term medication in a dog. Korean J Vet Clin 2005, 22:170-173.

23. Lee SE, Song KH, Lee SH: Survey of Ehrlichia canis and Borrelia burgdorferi antibodies in dogs (German shepherd) reared in Korea. Korean J Vet Res 2007:281-284.

24. O'Connor TP, Hanscom JL, Hegarty BC, Groat RG, Breitschwerdt EB Comparison of an indirect immunofluorescence assay, western blot analysis, and a commercially available ELISA for detection of Ehrlichia canis antibodies in canine sera. Am J Vet Res 2006, 67:206-210.

25. Lee D, Kim SH, Hong SK, Seo JK, Sung HS, Hwang SW: A case of Lyme disease with various general symptoms (Case Report). Korean $\rfloor$ Dermatol 2008, 46:1112-1116.

26. Park KH, Lee SH, Chang WH, Won WJ, Chang WJ: Isolation of Borrelia burgdorferi, the causative agent of Lyme disease, from Ixodes ticks in Korea. J Korean Soc Microbiol 1992, 27:307-312.

27. Solano-Gallego L, Llull J, Osso M, Hegarty B, Breitschwerdt E: A serological study of exposure to arthropod-borne pathogens in dogs from northeastern Spain. Vet Res 2006, 37:231-244.

doi: 10.1186/1756-3305-3-32

Cite this article as: Lim et al., Comparison of selected canine vector-borne diseases between urban animal shelter and rural hunting dogs in Korea Parasites \& Vectors 2010, 3:32

\section{Submit your next manuscript to BioMed Central} and take full advantage of:

- Convenient online submission

- Thorough peer review

- No space constraints or color figure charges

- Immediate publication on acceptance

- Inclusion in PubMed, CAS, Scopus and Google Scholar

- Research which is freely available for redistribution 